\section{Characterization of 'MD-2' Pineapple Planting Density and Fertilization Using a Grower Survey}

\author{
Ramon G. Leon ${ }^{1,3}$ and Delanie Kellon ${ }^{2}$
}

AdDitional Index words. Ananas comosus, fruit size, farm size, collaboration, cultural practices

SUMMARY. 'MD-2' is the predominant pineapple (Ananas comosus) cultivar for fresh fruit export worldwide. Costa Rica is one of the most important producers and exporters of 'MD-2', and many growers in this country have switched to this crop. However, growers have expressed concerns about the limited technical information available about how to grow this cultivar. We conducted a survey to gather information about the production practices implemented by commercial pineapple growers in Costa Rica and use this information to describe the response of the crop to these practices. Planting density was the most limiting factor affecting yield. Average planting density was 62,594 plants/ha although planting densities above 70,000 plants/ha produced highest yields. Average yields were 7130 and 4723 boxes/ha for the mother plant and ratoon crops, respectively. Fruit weight ranged from 1.5 to $2.0 \mathrm{~kg}$ and was not evidently affected by planting density or fertilization. Fertilization levels were between 632 and $520 \mathrm{~kg} \cdot \mathrm{ha}^{-1}$ nitrogen $(\mathrm{N})$, 129 and $93 \mathrm{~kg} \cdot \mathrm{ha}^{-1}$ phosphorous $(\mathrm{P})$, and 400 and $340 \mathrm{~kg} \cdot \mathrm{ha}^{-1}$ potassium for the mother plant and ratoon crops, respectively. In focus groups, growers considered that $\mathrm{N}$ and $\mathrm{P}$ levels could be reduced by $20 \%$ and $66 \%$ respectively, without jeopardizing yield. Results indicated that management practices must be modified for the ratoon crop to avoid yield reductions. The present study illustrated how a collaborative effort in which growers share information about their production practices can generate valuable data needed to identify adequate practices when funding and technical support are not available to experimentally generate these type of data.

$\mathrm{E}$ xperimental studies to identify appropriate production practices are a frequent and important step in the development of optimal management strategies for all crops. However, this effort can be costly and in many cases requires a high level of technical knowledge. In many developing countries, research funding and technical expertise could be a limiting factor, so experimentally generated data about proper production practices might not be available to most growers or might not exist at all. In these situations, especially for a new crop, growers can try to adapt technologies from existing research data for similar cropping systems, but ultimately they must rely on their experience and common sense to

This research was possible due to the funding provided by Whole Foods, Inc.

We want extent our gratitude to all the growers and professionals who participated in the survey.

${ }^{1}$ University of Florida, IFAS, West Florida Research and Education Center, 4253 Experiment Drive, Highway 182, Jay, FL 32565

${ }^{2}$ EARTH University, Apartado 4442-1000, San Jose, Costa Rica

${ }^{3}$ Corresponding author. E-mail: rglg@ufl.edu. determine how to grow their crop. When this happens, it is likely that there will be large variability in production practices being implemented by different growers. By combining the results of all these different practices, it is possible to identify trends that could give growers a better understanding of practices that are most appropriate for maximizing yield as well as those that appear to be only marginally beneficial or even counterproductive, and therefore should be reduced or eliminated.

Costa Rica is the world's largest producer of 'MD-2' pineapple and of fresh pineapple grown for export, and is among the top five in area devoted to the crop together with Brazil (fresh fruit mostly for domestic consumption), Philippines (canned and fresh fruit production for export), Thailand, and Indonesia (both mainly canned fruit for export) (Food and Agriculture Organization - Statistics, 2010; U.S. Department of Agriculture, 2008). Although pineapple has been commercially produced in this country for almost five decades, it was only recently that there was a rapid increase in the planted area from $\approx 8000$ ha in the late 1990s to 20,000 ha in 2003 , and to a dramatic 45,000 ha in 2010 (Barquero, 201l; Quijandria et al., 1997). This fast growth in production area was not followed by an increase in the availability of technical information or assistance for all the new growers who were switching to pineapple from crops such as banana (Musa sp.), cassava (Manihot esculenta), papaya (Carica papaya), rice (Oryza sativa), and common bean (Phaseolus vulgaris), for which production practices are considerably different from those used in pineapple. Most of the research conducted in pineapple is done by private companies that do not make information available to the general public. For this reason, there has been a wide range of production practices used by Costa Rican growers not affiliated with the major pineapple producing and exporting corporations.

Although in the past the most cultivated cultivar was Smooth Cayenne because it produced high yields and large fruit, and the plants were vigorous and stress-tolerant, a rapid change in consumer preferences forced growers to switch to 'MD-2' (Bartholomew, 2009). This cultivar is preferred because of its sweetness and yellow color (Syahrin, 2011). However, 'MD-2' fruit tend to be smaller and the plants are less vigorous and more susceptible to biotic and abiotic stresses than 'Smooth Cayenne'. Furthermore, 'MD-2' plants are particularly susceptible to natural flowering, which is believed to be caused, at least in part,

\begin{tabular}{llll}
\hline $\begin{array}{l}\text { Units } \\
\text { To convert U.S. to SI, } \\
\text { multiply by }\end{array}$ & U.S. unit & SI unit & $\begin{array}{l}\text { To convert SI to U.S., } \\
\text { multiply by }\end{array}$ \\
\hline 0.4047 & $\mathrm{acre}(\mathrm{s})$ & $\mathrm{ha}$ & $2.471 \mathrm{l}$ \\
0.3048 & $\mathrm{ft}$ & $\mathrm{m}$ & 3.2808 \\
2.54 & $\mathrm{inch}(\mathrm{es})$ & $\mathrm{cm}$ & 0.3937 \\
0.4536 & $\mathrm{lb}$ & $\mathrm{kg}$ & 2.2046 \\
1.1209 & $\mathrm{lb} / \mathrm{acre}$ & $\mathrm{kg} \cdot \mathrm{ha}^{-1}$ & 0.8922 \\
28.3495 & $\mathrm{oz}$ & $\mathrm{g}$ & 0.0353 \\
2.2417 & ton/acre & $\mathrm{Mg}^{-\mathrm{ha}^{-1}}$ & 0.4461
\end{tabular}


by low temperatures and results in significant variations in fruit production and harvest timing (Kuan et al., 2005). Thus, the switch to 'MD-2' made pineapple production more challenging and risky, obligating growers to have a greater technical understanding of the crop to ensure success. Unfortunately, there is limited information about 'MD-2' growing requirements in the literature.

Planting density and fertilization are among the production factors that have the greatest influence on yield, therefore appropriate practices in these areas are critical for optimum production. Traditionally, pineapple production has used planting densities of around 30,000 plants /ha in lowinput systems (Rebolledo et al., 2000; Selamat and Masaud, 2005; Uriza-Avila et al., 2005), but the intensification of the crop has favored the use of higher planting densities that range from 50,000 plants/ha to more than 70,000 plants/ha (Hepton, 2003; Hung et al., 2011; Perez et al., 2005). Since pineapple growers in Costa Rica with no access to privately funded research on this crop have expressed interest in identifying planting densities for ' $\mathrm{MD}-2$ ' that maximize yield and fruit quality, the objective of the present study was to gather information about the production practices implemented by commercial pineapple growers in this country and use this information to describe the response of the crop to these practices. Thus, growers who have no access to experimental data could identify appropriate practices for 'MD-2' production using a collaborative approach based on information/experience sharing, but the results must be evaluated in the light of sustainability and best management practices.

\section{Materials and methods}

The survey was conducted between March and Dec. 2011 in the northern and Atlantic regions of Costa Rica where most of the pineapple production is located $(\approx 67 \%)$ (Fig. 1). The survey was designed to generate information about efficiency in different aspects of pineapple production including planting, fertilization, pest management, soil management, harvest and postharvest, economics, and collaboration among growers. In the present article, only aspects related to effects of planting and fertilization on yield are discussed.

Growers were contacted by telephone or e-mail to request their

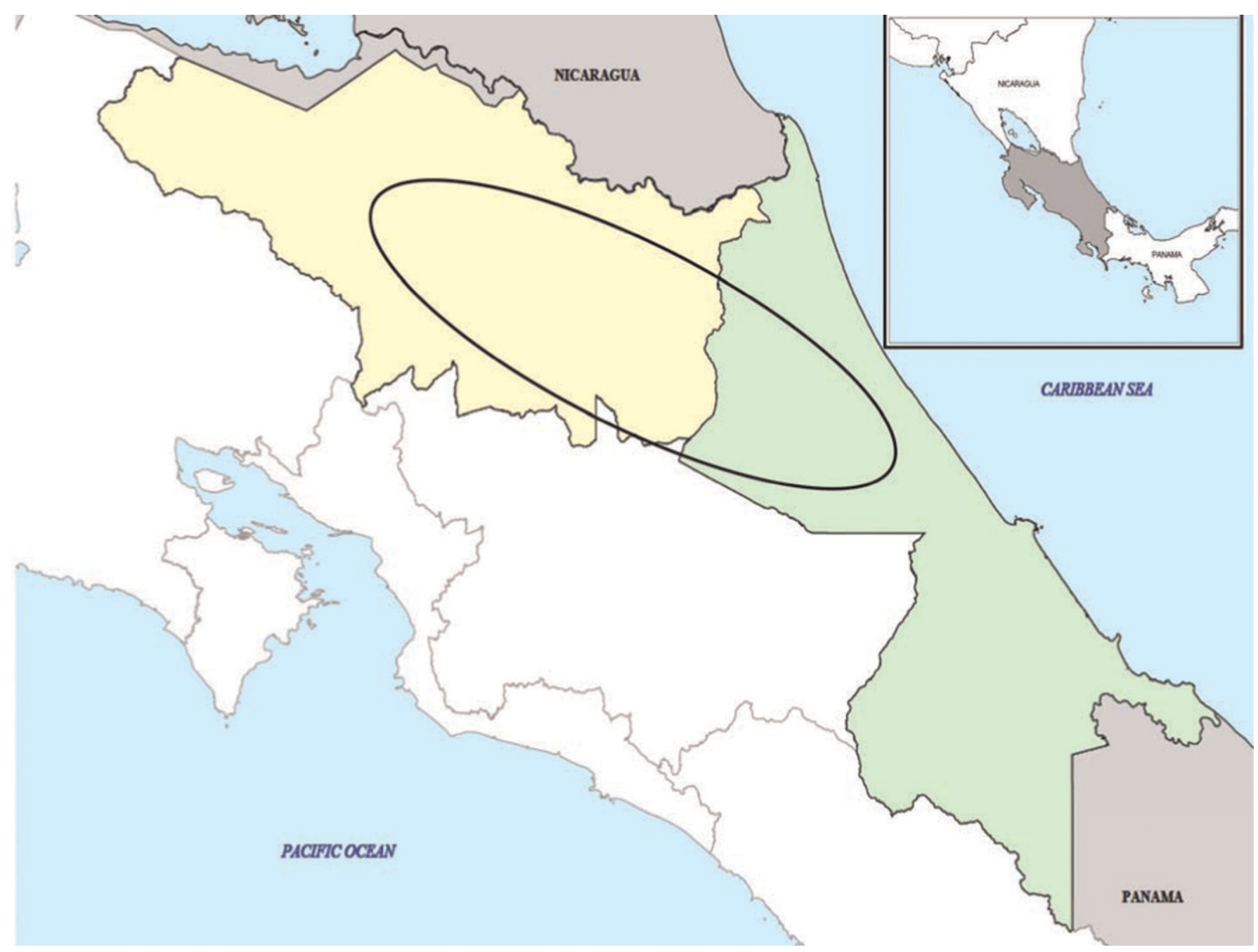

Fig. 1. Area where pineapple grower survey was conducted in Costa Rica. The colored area shows the northern and Atlantic regions where most of the 'MD-2' pineapple production is located. The circled area indicates the area where 44 farms were surveyed. The insert shows the location of the country in Central America. 
participation in the survey, and a personal appointment was set with those willing to share information about their production practices. The survey was conducted at the farm, and the person interviewed was either the owner of the farm or the general or production manager to ensure that the information provided was accurate. Quantitative and open discussion questions were formulated. For the quantitative questions, growers were asked to provide average values based on their records for: planting density; amounts of $\mathrm{N}, \mathrm{P}$, and potassium (K) applied; total yield; fruit size; and packing efficiency for the mother plant and ratoon crops. Most growers provided fruit size data only for the mother plant crop and did not provide details about fertilizer formulations and fertilization application timing. For the open discussion questions, growers were asked to explain their selection of production practices and their opinion about the results obtained. After the survey was conducted and the data analyzed, four focus groups were convened with a subsample of the interviewed growers to document their interpretation and explanation of the results.

Farms were arbitrarily classified as small, medium, and large. Small farms had less than 50 ha planted with pineapple and had no packing plant. Medium size farms had a planted area of 50 to 250 ha and had their own packing plant. Large farms had a planting area greater than 250 ha and also had a packing plant. This classification was important to take into consideration the level of technical resources available to growers when determining the sample and avoid bias toward any specific type of farm. In general, large farms have more resources (inputs, equipment, financing) than small or some medium farms. The statistical component of SigmaPlot 11.2 (Systat, San Jose, CA) was used to conduct linear and nonlinear regression analyses to identify the equations that best described the relations between the different variables, and $t$ tests were used to make specific comparisons between mother plant and ratoon crops. When fruit size was reported as the number of fruit packed in a box containing $25 \mathrm{lb}$ of total fruit weight, these data were transformed to report average fruit weight. Answers or values were not included in the analysis when the respondent expressed reservations about their accuracy or consistency over time.

\section{Results and discussion}

A total of 51 farms were contacted, and 44 agreed to participate in the survey for a response rate of 0.85 . Not all participating farms answered all questions, but for all variables there was an effective response rate above 0.77 . This sample included 12 small, 16 medium, and 16 large farms. All the farms identified themselves as independent, meaning that they were not owned by the pineapple growing and exporting corporations. Also, they reported growing exclusively 'MD-2', and had no research program or direct access to one. Ninety-three percent of the farms maintained their pineapple production area under a monoculture system.
Only 7\% of the farms reported growing pineapple as part of a crop rotation system. The survey covered a total of 24,637 ha of farmland with an effective pineapple planted area of 13,698 ha. Costa Rica's total pineapple planted area is $\approx 45,000$ ha, from which two-thirds are in the regions where the survey was conducted. Based on this, the survey covered $30 \%$ of country's planted area, and $47 \%$ of the pineapple production of the northern and Atlantic regions combined. Based on the information provided by growers, $90 \%$ of the farms were located in flat areas (less than 15\% slope), and the soil textures were clay $(36 \%$ of respondents), clay loam $(30 \%)$, loam (12\%), sandy loam $(14 \%)$, sand $(6 \%)$, and the remaining farms $(2 \%)$ did not answer.

YIELD. The average reported yield for the mother plant crop was

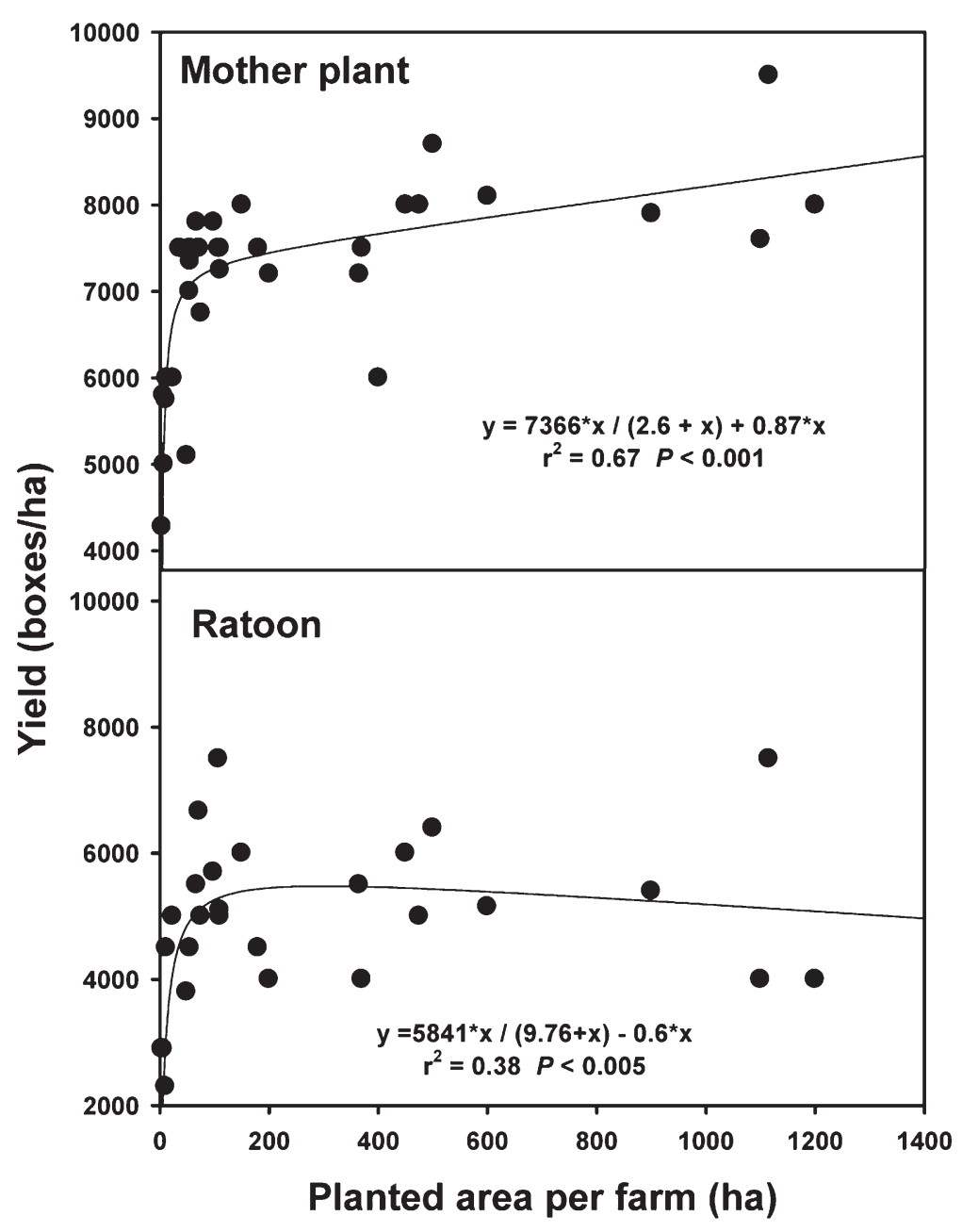

Fig. 2. Marketable 'MD-2' pineapple fruit yield for the mother plant and ratoon crops based on planted area on 44 farms in Costa Rica in 2011. The data were best fit using hyperbola-single rectangular II equations; 1 ha $=2.4711$ acres, 1 box $=25$ $\mathrm{lb}=11.3 \mathrm{~kg}, 1 \mathrm{box} / \mathrm{ha}=0.4047$ box $/$ acre . 
7130 25-lb boxes per hectare. This value represents the amount of fruit that met the quality standards for packing and export. Overall, the packed fruit represented $80 \%$ to $90 \%$ of the fruit produced in the field (data not shown). There was a positive relation between planted area and yield (Fig. 2). Yield started to reach a threshold at $\approx 8000$ boxes/ha, although two farms produced more than 8696 boxes/ha. Below 100 ha, there was a rapid decline in yield as planted area decreased.

Many growers obtain a ratoon crop $\approx 7$ months after the harvest of the mother plant crop. The average yield for the ratoon crop was 4783 boxes/ha and the yield threshold was around 6000 boxes/ha (Fig. 2). This represented a $35 \%$ reduction compared with the mother plant crop although there was significant variation. However, several farms reported only $11 \%$ reduction, while on other farms yield was reduced by more than $50 \%$. Those growers with minimum yield reductions between crops mentioned that they implement specific management practices to promote vigor in the ratoon crop, which represents additional efforts, while many of the growers with high yield reductions in the ratoon crop recognized only pruning the plants after the plant crop harvest and then going back to the regular management without taking any additional measures.

There was no evident relationship between fruit size and yield (Fig. 3) suggesting that fruit size by itself is not the most limiting component for maximum yield determination.

Vegetative Propagules. Growers used vegetative propagules with a weight range of 400-700 g (41\% of respondents), less than $400 \mathrm{~g}$ (39\%), or more than $700 \mathrm{~g}(18 \%)$. The types of propagules were slips and lateral shoots (90\% respondents), basal suckers $(75 \%)$, and crowns $(57 \%)$. When planting an area, growers only use one type of propagule to ensure uniformity. Selection of a specific propagule type usually depends on availability and projected harvest date, generally choosing smaller or larger propagules for longer or shorter growing periods, respectively.

Planting Density. Propagules are commonly planted in raised beds with two rows of pineapple plants. Beds are generally spaced at $3.5 \mathrm{ft}$ and planting rows at 18 inches. Planting density is modified by varying the distance between plants within the row. There was a positive relation between farm size and planting density in which the largest variation was observed in small and medium size farms (Fig. 4). Average planting density was 62,594 plants/ha although the reported densities ranged from 35,000 to 74,200 plants/ha.

Planting density was a determinant factor for yield especially for the mother plant crop (Fig. 5), which was evident in the positive linear response between these two variables $\left(r^{2}=0.66\right.$, $P<0.001)$. The ratoon crop also showed a positive relation, but with a higher level of variability $\left(r^{2}=0.24\right.$, $P=0.01$ ).

Previous reports for other cultivars such as Smooth Cayenne indicated that densities of 30,000 plants/ha allowed maximizing fruit size ( $2.42 \mathrm{~kg}$ per fruit including crown) and that above this density fruit size decreased rapidly (Perez et al., 2005). However, fruit of that size are not

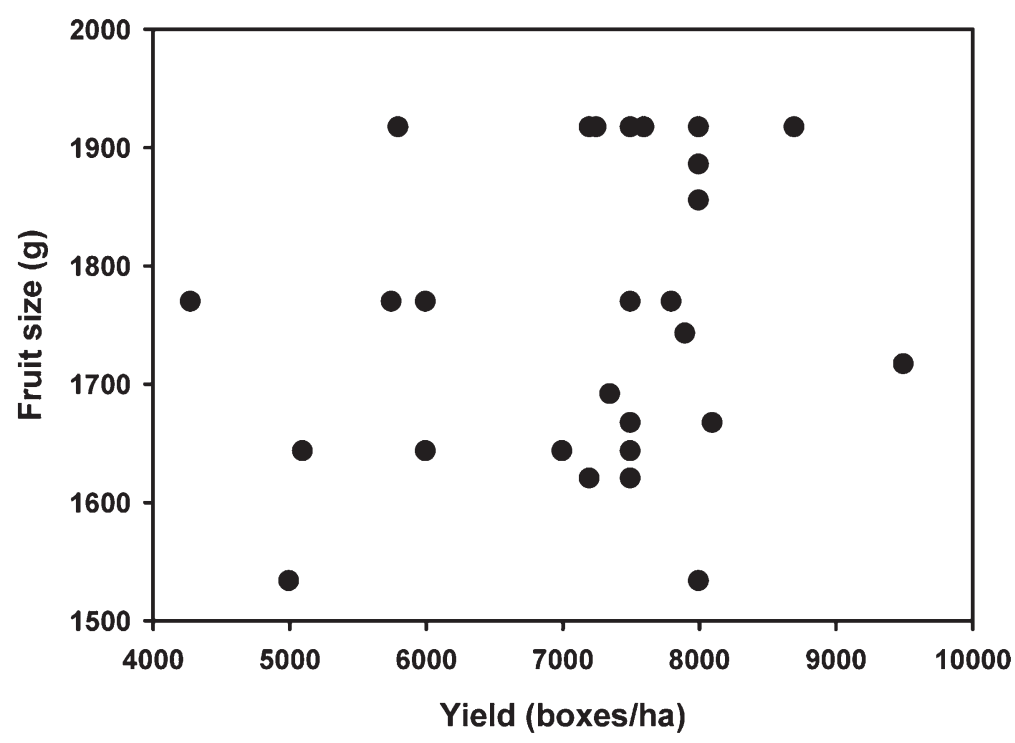

Fig. 3. Relationship between 'MD-2' marketable fruit yield and size for the mother plant crop on pineapple 27 farms in Costa Rica in 2011; 1 box $=25 \mathrm{lb}=11.3 \mathrm{~kg}$, $1 \mathrm{box} / \mathrm{ha}=0.4047$ box $/$ acre, $1 \mathrm{~g}=\mathbf{0 . 0 3 5 3} \mathrm{oz}$.

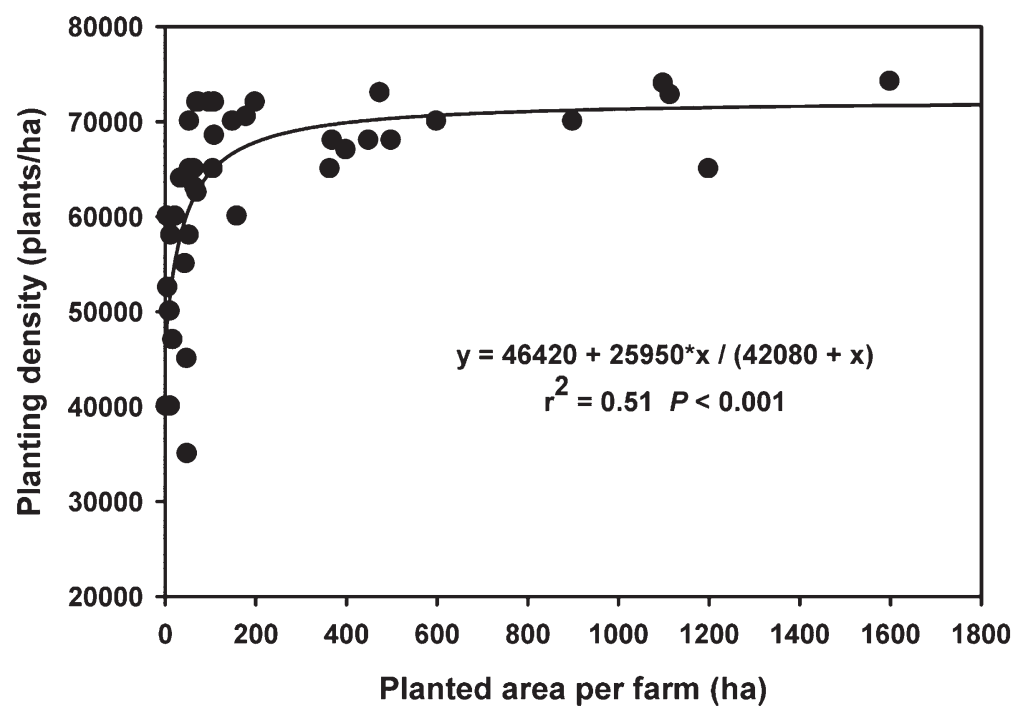

Fig. 4. Relationship between planting density and hectares planted to 'MD-2' pineapple for $\mathbf{4 4}$ farms in Costa Rica in 2011. The data were best fit using a hyperbola-single rectangular I equation; $1 \mathrm{ha}=\mathbf{2 . 4 7 1} \mathrm{l}$ acres, 1 plant $/ \mathrm{ha}=\mathbf{0 . 4 0 4 7}$ plant/acre. 
desirable in the export market; instead fruit with a weight of 1.6 to $1.9 \mathrm{~kg}$ are usually preferred by the average consumer. Growers using low planting densities explained that they prefer to leave more space between plants to minimize competition and ensure the production of large fruit $(\approx 1.8-2.0 \mathrm{~kg}$ per fruit), which usually translate into higher prices. Also, they were aware that this practice meant sacrificing yield, although they were not sure by how much. Despite the intuitively logical assumption that less competition between plants should allow for the production of larger fruit, small growers who regularly used low planting densities were the most likely to produce small fruit (Fig. 6). A recent study evaluating higher planting densities for 'Smooth Cayenne' indicated that the maximum yield of $86 \mathrm{Mg} \cdot \mathrm{ha}^{-1}(\approx 7478$ boxes/ha) was achieved at 66,000 plants/ha and that increasing the density to 78,000 plants/ha caused an $\approx 18 \%$ yield decrease (Hung et al., 2011). In this case, fruit weight ranged between $1.2 \mathrm{~kg}$ in densities above 71,000 plants / ha to $1.6 \mathrm{~kg}$ for densities below 66, 000 plants/ha. In the present study, although at high planting densities more growers reported smaller fruit, a significant number of farms that had planting densities above 70,000 plants/ha consistently produced large fruit (Fig. 7). Furthermore, the highest total yields (above 7826 boxes/ha) were obtained with the highest planting densities (above 68,000 plants/ha), and those farms also reported average fruit weights of 1.75 to $1.90 \mathrm{~kg}$. This point is particularly important because it seems that there is still potential to increase planting density in 'MD-2' pineapple. In fact, in the focus groups, several large growers stated that they had begun using planting densities above 76,000 plants/ha, and by maintaining an adequate fertilization program they increased their yields and the average fruit size had not been significantly reduced. However, they acknowledged that there is a higher risk of obtaining small fruit at this planting density if production practices are not implemented in a timely manner or if there are stressful growing conditions (e.g., irregular rainfall, severe pest or disease problems, weather conditions favoring natural flowering). Growers pointed out that another advantage of using

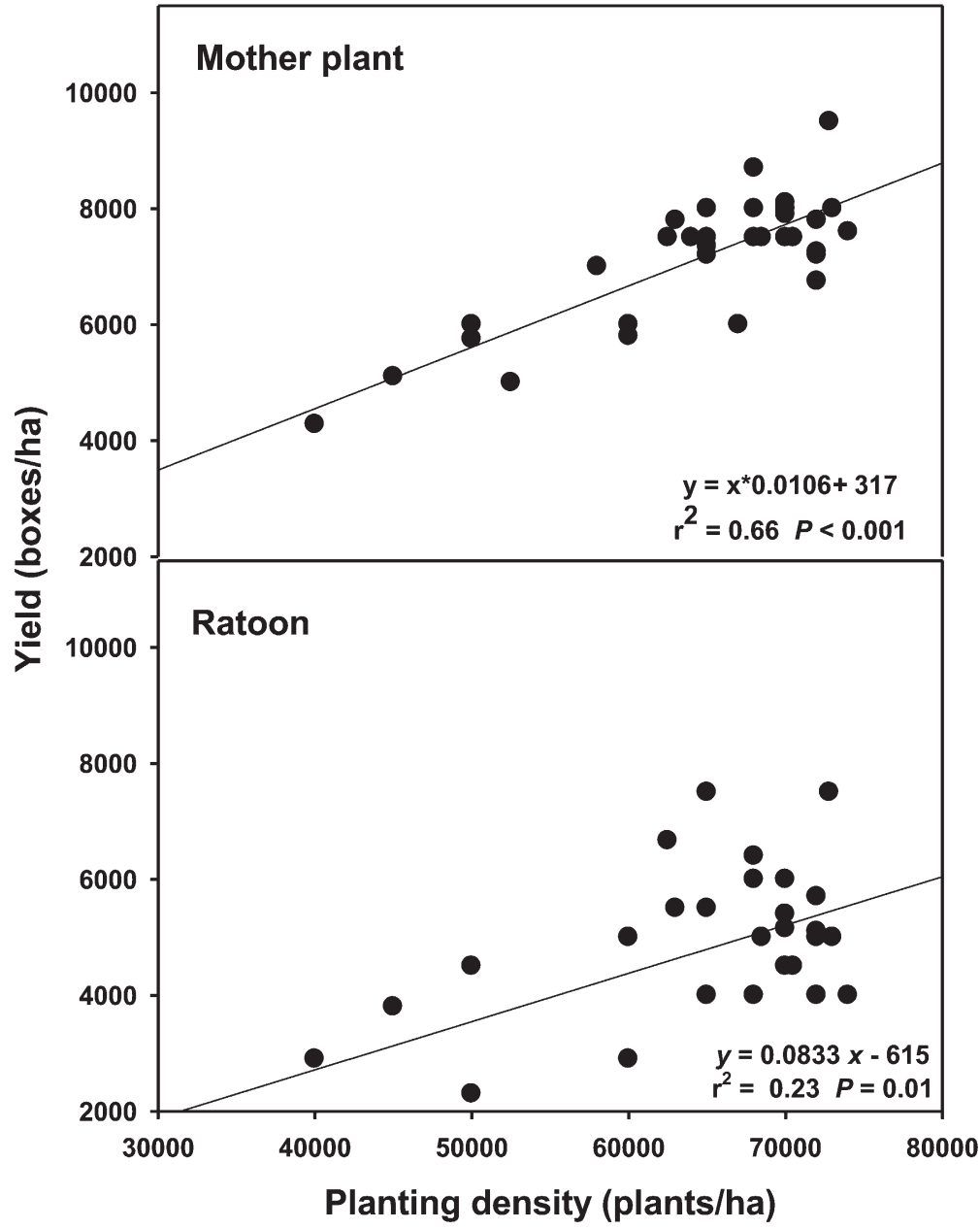

Fig. 5. Marketable fruit yield for the mother plant (33 farms) and ratoon crops (27 farms) as affected by planting density on 'MD-2' pineapple farms in Costa Rica in 2011. The data were best fit using polynomial linear equations; 1 ha $=2.4711$ acres, 1 box $=25 \mathrm{lb}=11.3 \mathrm{~kg}, 1$ box $/ \mathrm{ha}=0.4047 \mathrm{box} /$ acre .

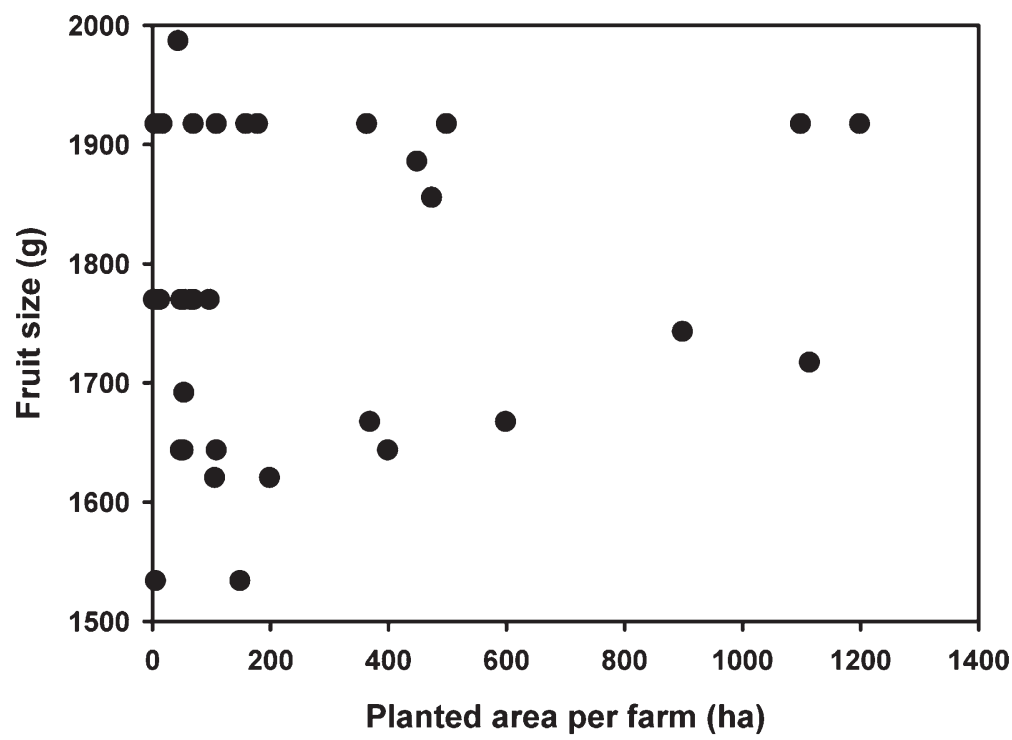

Fig. 6. Relation between marketable fruit size in the mother plant crop and planted area per farm on 37 'MD-2' pineapple farms in Costa Rica in 2011; 1 ha $=2.4711$ acres, $1 \mathrm{~g}=\mathbf{0 . 0 3 5 3} \mathrm{oz}$. 
high planting densities is that the efficiency of foliar fertilizer applications is higher because more fertilizer is intercepted by the plants. Additionally, a denser crop canopy is also more competitive against weeds, so the need for hand weeding is reduced by the use of high densities. It is important to mention that maximum fruit size is highly determined by plant weight at the time of forcing. Thus, it is likely that those growers that have increased their planting densities and have maintained fruit size have also been able to maintain plant weight at the time of forcing.

Fertilization. Growers predominantly described their fertilization system as comprised of a basic soil application at planting (less than $20 \%$ of total fertilization with $\mathrm{N}, \mathrm{P}$, and $\mathrm{K}$ ) followed by foliar applications with soluble forms using a spray-boom at regular intervals of about two weeks until harvest. Most growers did not report using soil or leaf analyses to determine fertilization requirements. Those growers that reported the use of leaf analyses indicated that they used them for micronutrient deficiencies and not for $\mathrm{N}, \mathrm{P}$, or $\mathrm{K}$. Their assumption is that axillary roots at the basal area of the leaf axis are the most efficient nutrient absorption system in pineapple plants, so supplying foliar fertilizers should suffice to fulfill the requirements of the crop. In spite of this, it is still possible that soil nutrients could significantly contribute to pineapple growth. There was no clear relation between yield and fertilizer rates, or planting density and fertilizer rates $\left(r^{2}<0.17\right.$ and $\left.P>0.37\right)$. However, although there was a large variation in fertilization levels, it is worth noting that the farms with the highest yields had fertilization programs that were close to the median for each nutrient (Fig. 8). Although small growers had an average planting density that was $24 \%$ lower than the average planting density on large farms, they also applied half the amounts of $\mathrm{N}$ and $\mathrm{K}$ applied by the large growers. Therefore, low fertilizer use resulted in small plants at the time of forcing, which could explain the small fruit size obtained by small growers even when using low planting densities. In the analysis of the results conducted with the focus groups, several growers from farms that were among those with the highest yields (top 20\%) considered that the average fertilization levels reported for nitrogen and phosphorus were "luxury rates" and that lower rates could be used without necessarily sacrificing yields. On the other hand, they considered the reported potassium levels (400 and $340 \mathrm{~kg} \cdot \mathrm{ha}^{-1}$ for the mother plant and ratoon crops, respectively) to be adequate. In their opinion, if efficient/calibrated applications are used, appropriate fertilization rates for the mother plant crop should be 500 to $580 \mathrm{~kg} \cdot \mathrm{ha}^{-1} \mathrm{~N}$ and 44 to $61 \mathrm{~kg} \cdot \mathrm{ha}^{-1} \mathrm{P}$, which represent about up to a $20 \%$ and $66 \%$ reduction, respectively, compared with the reported averages. These fertilization levels are lower than those provided in production manuals. For example, the manual of the Pesticides Initiative Program recommends for the mother plant and ratoon crops, respectively, 800 and $852 \mathrm{~kg} \cdot \mathrm{ha}^{-1} \mathrm{~N}$, 315 and $0 \mathrm{~kg} \cdot \mathrm{ha}^{-1} \mathrm{P}$, and 387 and

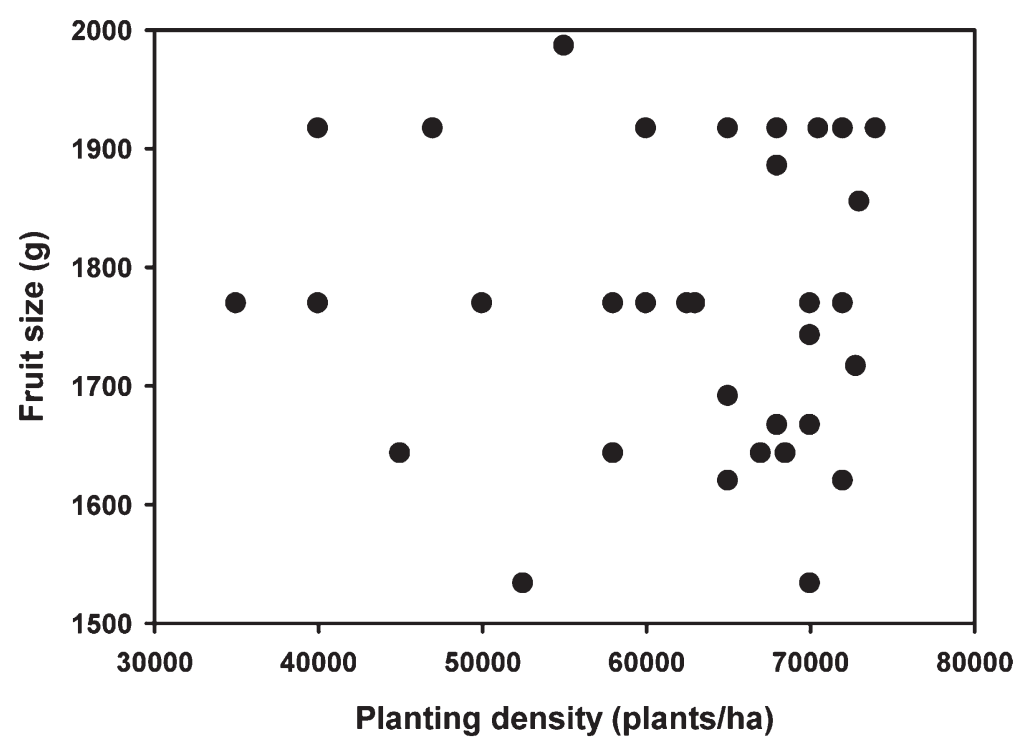

Fig. 7. Marketable fruit size in the mother plant crop affected by planting density on 37 'MD-2' pineapple farms in Costa Rica in 201 1; 1 plant $/$ ha $=0.4047$ plant $/$ acre, $1 \mathrm{~g}=0.0353 \mathrm{oz}$.

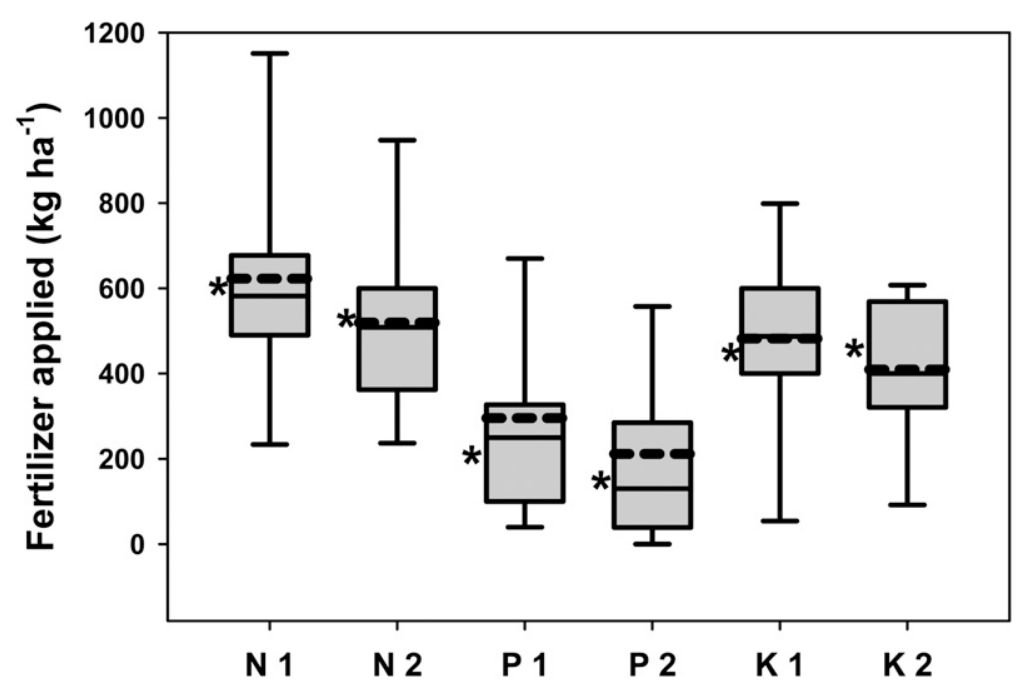

Fig. 8. Amount of nitrogen $(\mathrm{N})$, phosphorous $(\mathrm{P})$, and potassium $(\mathrm{K})$ supplied to 'MD-2' pineapple in mother plant (1) and ratoon (2) crops based on reports by growers on 44 pineapple farms in Costa Rica in 2011. The error bars show the range of responses; the middle, lower, and upper lines in the box show the median, and the 25 and 75 percentiles, respectively; the dashed line shows the mean; and the stars indicate the fertilization levels used by the highest yielding farms; $1 \mathrm{~kg} \cdot \mathrm{ha}^{-1}=$ $0.8922 \mathrm{lb} / \mathrm{acre}$. 
$542 \mathrm{~kg} \cdot \mathrm{ha}^{-1} \mathrm{~K}$ at a planting density of 70,000 plants/ha (Sanchez, 2005). Therefore, it seems that growers, especially those obtaining the highest yields, have been able to optimize their fertilization programs and reduce fertilizer rates compared with common recommendations.

The reduction in fertilizer amounts was not proportional to the reduction in yield when comparing the mother plant and ratoon crops. For example, nitrogen and potassium fertilization was reduced by only $\approx 15 \%$ and phosphorus by $28 \%$, while the overall yield reduction was around $35 \%$. It is possible that the yield reduction is a consequence of limited fertilization. As mentioned before, common recommendations even suggest increasing $\mathrm{N}$ and $\mathrm{K}$ levels in the ratoon crop (Sanchez, 2005), although technical bases for this are not clear. However, there is a need for developing production practices that better respond to the requirements of the ratoon crop. To develop efficient fertilization programs, growers should base these programs on soil and leaf analyses taking into consideration crop requirements and soil specific characteristics of each farm.

Finally, the results illustrated how a collaborative effort in which growers share information about their production practices can generate valuable data needed to identify adequate practices when funding and technical support are not available to experimentally generate this type of data.

\section{Literature cited}

Barquero, M. 2011. Área sembrada de piña se duplicó en últimos cuatro años. 8 Aug. 2011. <http://www.nacion.com/ 2011-08-08/Economia/Area-sembradade-pina-se-duplico-en-ultimos-cuatroanos.aspx>.

Bartholomew, D.P. 2009. 'MD-2' pineapple transforms the world's pineapple fresh fruit export industry. Pineapple News 16:2-5.

Food and Agriculture Organization Statistics. 2010. Crop: Pineapple. 16 May 2012. <http://faostat.fao.org/site567/ deault.aspx\#ancor>.

Hepton, A. 2003. Cultural System, p. 109142. In: D.P. Bartholomew, R.E. Paul, and K.G. Rohrbach (eds.). The pineapple: Botany, production and uses. CABI Intl., New York.

Hung, N.Q., D.K. Thoa, and N.T.T. Huong. 2011. Effect of planting density on growth, development and yield of irrigated pineapple in Nghe An Province. Acta Hort. 902:307-311.

Kuan, C.S., C.W. Yu, M.L. Lin, H.T. Hsu, D.P. Bartholomew, and C.H. Lin. 2005. Foliar application of aviglycine reduces natural flowering in pineapple. HortScience 40:123-126.

Quijandria, G., J. Berrocal, and L. Pratt. 1997. La industria de la piña en Costa Rica, análisis de sostenibilidad. Latin
American Ctr. Competitiveness Sustainable Dev. (CLADCS)-INCAE Business School, Alajuela, Costa Rica. CEN 707.

Perez, P.G., M.P.G. Garcia, L.M. Rebolledo, D.A. Uriza, A.A.C. Tinoco, and A.M. Rebolledo. 2005. Planting densities and plastic mulching for 'Smooth Cayenne' pineapple grown in an $\mathrm{AW}_{2}$ climate fluvisol soil in Veracruz, Mexico. Acta Hort. 666:271-275.

Rebolledo, M.A., D.E.A. Uriza, and M.L. Rebolledo. 2000. The pineapple in Mexico: Current status and prospects. Acta Hort. 529:85-88

Sanchez, M.L.A. 2005. MD2 pineapple variety production guide. Pesticide Initiative Programme, Europe-Africa-CaribbeanPacific Liasson Committee. Brussels, Belgium.

Selamat, M.B.M. and R. Masaud. 2005. Growth, yield and quality of pineapple cv. Josapine as affected by density and fertilizer rate grown on sandy soil in Malaysia. Acta Hort. 666:193-201.

Syahrin, S. 2011. Consumer preferences towards pineapple cultivars in Malaysia. Acta Hort. 902:595-599.

Uriza-Avila, D., A. Rebolledo-Martinez, and L. Rebolledo-Martinez. 2005. Diagnostic and perspectives of pineapple cropping in Mexico. Acta Hort. 666:29-39.

U.S. Department of Agriculture. 2008. Pineapples: U.S. import-elegible countries, world production and exports. 16 May 2012. <http://www.ers.usda.gov/data/ fruitegphyto/Data/fr-pineapples.xls $>$. 